\title{
Generation Means Analysis for Five Physiological Traits of Bread Wheat under Rainfed Condition
}

\author{
Usman Ijaz ${ }^{1, *}$, Smiullah $^{1}$, Muhammad Kashif ${ }^{2}$ \\ ${ }^{1}$ Ayub Agriculture Research Institute, Faisalabad, Pakistan \\ ${ }^{2}$ Department of Plant Breeding \& Genetics, University of Agriculture, Faisalabad, Pakistan \\ *Corresponding Author: usmanpbg@gmail.com
}

\section{Copyright $@ 2013$ Horizon Research Publishing All rights reserved}

\begin{abstract}
To understand the genetics of drought tolerance, two promising elite lines V-04189 and V-03138 were crossed to develop $\mathrm{F}_{1}, \mathrm{~F}_{2}$ and back cross generations $\left(\mathrm{BC}_{1}\right.$ and $\left.\mathrm{BC}_{2}\right)$. Six generations $\left(\mathrm{P}_{1}, \mathrm{P}_{2}, \mathrm{~F}_{1}, \mathrm{~F}_{2}, \mathrm{BC}_{1}\right.$ and $\left.\mathrm{BC}_{2}\right)$ were raised with no recommended irrigations. Analysis of variance showed presence of sufficient genetic variability among six generations. Hybrid vigor was observed in most of the cases except flag leaf area. Generation means analysis revealed two parameter model [md] provided the best fit for relative water contents and excised leaf water loss which shows the presence of additive genetic effect is prominent with simple inheritance The remaining traits exhibited higher parameter models and indicating complex inheritance. Generation means analysis indicating the presence of additive genetic affects that can be fixed in early segregating generations.
\end{abstract}

Keywords Generation mean analysis, genetic variability

\section{Introduction}

Pakistan is an agricultural country. Agriculture is the backbone of Pakistan's economy and provides occupation to two third of the country's population. Water is the blood of crop which requires for certain metabolic activities and in the absence of water growth and development of plant ceases. Cultivated land in Pakistan is ranged from arid to semi-arid and deficient in water. In spite of having world's best canal irrigation, a large cultivated area (1.1 million ha) is rainfed with very low potential yield, Pakistan statistical year book, [1]. Developing wheat varieties with low moisture requirement and cope well with moisture stress is the only answer to overcome the oncoming perils. Evolution of wheat varieties with low moisture requirements is a long, hard and complex process, when the objective involved is the inclusion of high grain yield. Conventional and non-conventional means to create variability where selection is focus on grain yield and seeks out the character other than yield that may have an agronomic edge under water unavailability.

Photosynthesis is an essential event for plant growth that requires water as an essential ingredient. High leaf water potential and relative water contents increases the photosynthetic rate which were greatly reduced by water unavailability (Siddique et al., [2]: Bajji et al., [3]: Sairam and Srivastava [4] and Tas and Tas, [5]). High stomata frequency on flag leaf increased grain yield but under limited water it is undesirable (Yousufzai et al., [6]). Talebi et al., [7] reported that selection from moisture limited environment would improve yield for drought tolerance than non-stress. Khattab et al., [8] revealed that epistatic gene effect create complexity and it cannot be overlooked in a new breeding program to improve wheat genotypes for economic traits. Khazaei et al., [9] reported significant variation among the wheat diploid, tetraploid and hexaploid species and found that stomatal frequency decreases from diploid to tetraploid and hexaploid which is reverse in case of stomatal length and width. Plant breeder has suggested to use morphological and physiological plant traits as a selection criteria for yield improvement (Farshadfar et al. [10] and Kumar and Sharma [11]). Sharma and Sharma [12] concluded that hybridization system, such as biparentals mating and/or diallel selective mating which exploited both additive and non-additive genetic effects.

Biometrical techniques always helping plant breeders to understand genetic components of crop plants. Most reliable technique to study gene action were described by Mather and Jinks [13] which implies at first degree statistics. For breeding drought tolerant wheat cultivars, availability of genetic variability and knowledge of gene action is needed otherwise it may not result in an appreciable improvement. The objective of present study is to evaluate six generations $\left(\mathrm{P}_{1}, \mathrm{P}_{2}, \mathrm{~F}_{1}, \mathrm{~F}_{2}, \mathrm{BC}_{1}\right.$ and $\left.\mathrm{BC}_{2}\right)$ of bread wheat to understand the gene action involved for better performance in rainfed environment.

\section{Materials and Methods}

Out of twenty six promising wheat lines from national 
uniform wheat yield trial (NUWYT) 2008-09, two elite lines V-04189 and V-03138 were selected on their higher performance in trial. Seed of the parents V-04189, V-03138 and hybrid (V-04189 $\times$ V-03138) grown at the crop research area of Deptt. Plant Breeding and Genetics, University of Agriculture, Faisalabad, Pakistan, during wheat crop season 2009-10 to develop $F_{2}$ and back crosses.

After booting, at anthesis selected spikes from parents and hybrid were crossed to develop, $\mathrm{BC}_{1}\left(\mathrm{~V}-04189 \times \mathrm{F}_{1}\right), \mathrm{BC}_{2}$ $\left(\mathrm{V}-03138 \times \mathrm{F}_{1}\right)$ and some selected spikes from $\mathrm{F}_{1}$ covered with butter paper bag to develop $F_{2}$ generations. All the precautionary measures adopted during crosses to avoid contamination. Seed of crosses and parents were harvested and threshed separately to avoid mechanical mixing and store under optimum conditions. The parents (V-04189, $\mathrm{V}-03138), \mathrm{F}_{1}, \mathrm{~F}_{2}$ and back cross $\left(\mathrm{BC}_{1}\right.$ and $\left.\mathrm{BC}_{2}\right)$ generations were sown with pre-irrigation (no further irrigation) in triplicate by using randomized complete block design and subjected to complete their growth under rainfall during 2010-11. A single row for parents and $F_{1}$ generations, two rows for each back cross and five rows for $F_{2}$ generation were planted. The length of each row was five meters. Inter-row and inter-plant distance was kept $9 \mathrm{~cm}$. Normal cultural practices except irrigation applied to the generations throughout their growing period.

Five plants were selected randomly for data recording from each row for each parent, $F_{1}$, twenty plants for back crosses and twenty five plants for $\mathrm{F}_{2}$ generation in each replication. Data were recorded on the following traits when the plants were green and leaves were in fully expanded condition.

\subsection{Flag Leaf Area $\left(\mathrm{cm}^{2}\right)$}

From the fully developed flag leaf of selected mother shoots, the maximum length and width was measured in centimeters. The data were recorded in the morning hours when leaf was fully turgid. Flag leaf area was calculated using the following function of Muller [14], Flag leaf area = Flag leaf length $\times$ Flag leaf Width $\times 0.74$

\subsection{Relative Water Contents (RWC)}

The second leaf of each selected plants taken (in all the generations) to measure RWC. Leaf samples collected early in the morning were surface dried with the help of tissue paper and wrapped in polythene bag. Leaf samples were taken to the lab immediately and leaves were weighted to measure fresh weight $(\mathrm{FW})$. These leaves were soaked in distal water overnight at room temperature to revive turgidity. The turgid leaves were blot to dry gently and weighted to measure turgid weight (TW). Turgid leaves were oven dried for 72 hours at $70^{\circ} \mathrm{C}$ and dry weight (DW) was recorded with the help of electronic balance (COMPAX model no. CX-600). The RWC was calculated by the following formula as given by Rahman et al. [15]

$$
\text { RWC }(\%)=[(F W-D W) \div(\text { TW-DW })] \times 100
$$

\subsection{Excised Leaf Water Loss (ELWL)}

Excised leaf water loss study carried out on third leaf (in all generations) and leaf samples were collected exactly the same way as for RWC above. Fresh weight of the excised leaf measured soon after collection in the field and leaf samples were spread on laboratory bench for six hours at room temperature. After six hours leafs were weighted again to obtain wilted weight than leaves were oven dried for 72 hours at $70^{\circ} \mathrm{C}$ and dry weight was recorded with the help of electronic balance (COMPAX model no. CX-600). ELWL calculated using the following equation (Rahman et al., [15]).

$$
\text { ELWL }=(\text { Fresh weight }- \text { Wilted weight }) \div \text { Dry weight }
$$

\subsection{Stomatal Frequency}

Number of stomata per microscopic field at 10X magnification was counted for flag leaf of the mother shoot of each selected plant. Five strips were taken from the middle part of the flag leaf at the time when it was fully expanded. These strips were dipped into carnoy's solution to arrest the stomatal movement and removal of chlorophyll from the leaf tissue. After 48 hours, the strips were washed with acetone and stored in $70 \%$ ethyl alcohol for further examination.

\subsection{Stomatal Size $(\mu \mathrm{m})$}

Size of the stomata was measured in microns. An ocular micrometer (scaled at $10 \mathrm{~mm}$ ), standardized using a $1.0 \mathrm{~mm}$ stage micrometer, was used. Each unit of ocular micrometer was found to be equal to 3.33 microns at $40 \mathrm{X}$ at the time of standardization. Length and width of three stomata per five strips was measured to calculate stomatal size and average stomatal size computed.

Data on individual plant basis on second and third leaf for RWC and ELWL, along with flag leaf for stomatal frequency and stomatal size under water deficient condition. Analysis of variance carried out to access significant differences between generation means according to Steel et al., [16]. Generation means analysis was performed following the procedure Mather and Jinks [13].

\section{Results and Discussion}

\subsection{Flag leaf area $\left(\mathrm{cm}^{2}\right)$}

The six generations $\left(\mathrm{P}_{1}, \mathrm{P}_{2}, \mathrm{~F}_{1}, \mathrm{~F}_{2}, \mathrm{BC}_{1}\right.$ and $\left.\mathrm{BC}_{2}\right)$ of a cross V-03138 $\left(\mathrm{P}_{1}\right) \times \mathrm{V}-04189\left(\mathrm{P}_{2}\right)$ showed significant differences $(\mathrm{P} \leq 0.05)$ for flag leaf area (Table 1). Table 2 also depicted that the calculated flag leaf area of $F_{1}\left(34.96 \mathrm{~cm}^{2}\right)$ cross combination is between the two parents, which showed higher mean value over $\mathrm{P}_{2}\left(34.33 \mathrm{~cm}^{2}\right)$ and lesser than $\mathrm{P}_{1}$ $\left(37.23 \mathrm{~cm}^{2}\right)$.

The generation means analysis revealed three parameters model [mdi] showed the best fit for flag leaf area from 
observed to expected generation means (Table 3). The additive genetic effects [d] significantly involved in the inheritance of flag leaf area and indicated that the selection in early segregating generations is useful. The positive and higher value of single epistatic effect (i) makes it possible to fix the additive $\times$ additive genetic effect to increase the flag leaf area. Importance of flag leaf area cannot be doubted for grain yield because it is the major site of photosynthesis and provides stored carbohydrates during grain filling. In this experiment it was observed that flag leaf area greatly reduced under rainfed condition (Nabipour et al, [17]). At post anthesis stage $98 \%$ reduction in the flag leaf area was observed by Kazmi et al, [18]. Flag leaf area considerably vary among different ploidy levels in wheat diploid $(2 \mathrm{n}=$ $2 X=14)$ species have highest flag leaf area, that's why they have high photosynthetic ability (Maosong et al, [19]). The genotype showed high flag leaf area is more productive under moisture stress due to better grain filling. Breeding cultivars for low moisture requirement flag leaf area can be utilized as an essential morphological marker.

The results revealed that flag leaf area is predominantly under the control of additive type of gene action which has been previously reported by Chowdhry et al. [20], Awaad [21], Chowdhry et al. [22], Subhani and Chowdhry [23], Ambreen et al. [24], Mahmood et al. [25], Riaz and Chowdhry [26], Inamullah et al. [27], Slaeem et al. [28] and Munir et al. [29].

\subsection{Relative water contents (RWC)}

Relative water contents indicate the amount of moisture present in leaf. It is an important physiological trait for breeding cultivars under water scarce condition. High relative water contents is foremost need of plant to be successful under limited water condition. Parents V-04189 $\left(\mathrm{P}_{1}\right) \mathrm{V}-3138\left(\mathrm{P}_{2}\right)$, first and second filial generations along with their back crosses showed significant differences $(\mathrm{P} \leq$ 0.01 ) for the relative water contents as displayed in Table 1.

The perusal of Table 2 indicated that hybrid $\left(F_{1}\right)$ showed highest (83.22) relative water contents between the treatments. Malik and Aeright [30] found that drought resistant and drought susceptible genotypes greatly differ for their relative water contents and drought resistant genotypes showed higher relative water contents. Rahman et al [15] found non-significant differences between the generations for relative water contents. Siddique et al [2] reported that higher relative water contents increase the photosynthetic rate. Water unavailability creates significant reduction in relative water contents ultimately decreasing photosynthesis as agreed by Bajji et al. [3] and Sairam and Srivastava [4] but, Tas and Tas [5] claimed that hexaploid cultivars showed higher relative water contents under limited water environment.

The generation means study revealed two parameter model [md] showed fit best for relative water contents (Table $3)$. The additive genetic effects [d] significantly involved in the inheritance of relative water contents and indicated that the selection in early segregating generations will be fruitful. Absence of epistasis makes it possible to fix the additive genetic effect to increase the relative water contents to achieve the goal of breeding cultivars for stress environment. In the absence of non-allelic interaction the additive genetic effect found to be outstanding as reported before by Farshadfar et al. [10], Golparavar et al. [31] and Kumar and Sharma [11].

\subsection{Excised leaf water loss (ELWL)}

Two parents were crossed V-04189 $\left(\mathrm{P}_{1}\right) \times \mathrm{V}-3138\left(\mathrm{P}_{2}\right)$ to develop $F_{1}, F_{2}$ along with their back crosses and all the generations showed significant differences $(\mathrm{P} \leq 0.01)$ for the excised leaf water loss studied under rainfed condition (Table 1). On viewing Table 2 it is revealed that hybrid $\left(F_{1}\right)$ showed higher value (4.61) of excised leaf water loss followed by $\mathrm{P}_{1}, \mathrm{~F}_{2}, \mathrm{BC}_{2}, \mathrm{BC}_{1}$ and $\mathrm{P}_{2}(4.59,4.07,3.87,3.82$ and 3.53 respectively).

The genetic analysis involved six generations in Table 3 revealed two parameter model [md] showed the best fit for excised leaf water loss. The additive genetic effects [d] significantly involved in the inheritance of excised leaf water loss and indicated that the selection in early segregating generations is useful. Absence of epistasis makes it possible to fix the additive genetic effect to control the excised leaf water loss to achieve the goal of breeding cultivars for better stress environment. Excised leaf water loss depicts the ability of leaf to maintain its turgidity when water is not available at field capacity. For breeding under rainfed condition low value of excised leaf water loss is needed because when moisture lost is plant will tend to survive stressful condition. This study reveals that excised leaf water loss is very sensitive to low moisture. In the absence of non-additive genetic effect breeder cannot go for hybrid because heterosis is insufficient to be utilized. In the absence of non-allelic interaction the additive genetic effect predominantly involved in the inheritance of excised leaf water loss as reported before by Farshadfar et al. [10] and Kumar and Sharma [11].

\subsection{Stomatal frequency}

Stomata are the site of gaseous exchange (intake of $\mathrm{CO}_{2}$ ) between the leaf and air. Large number of stomata on leaf will increase the $\mathrm{CO}_{2}$ intake ultimately increasing the photosynthesis. But, under stressful condition the higher stomata become a curse because $95 \%$ transpiration take place through stomata. Stomatal frequency showed significant differences $(\mathrm{P} \leq 0.01)$ among six treatments $\left(\mathrm{P}_{1}\right.$, $\mathrm{P}_{2}, \mathrm{~F}_{1}, \mathrm{~F}_{2}, \mathrm{BC}_{1}$ and $\mathrm{BC}_{2}$ ) presented in Table 1. According to the Table 2 hybrid $\left(\mathrm{F}_{1}\right)$ showed higher number of stomata (125.44) as compared to the parents $\left(\mathrm{P}_{1}=80.66\right.$ and $\mathrm{P}_{2}=$ 75.11). Nabipour et al [17] reported that under moisture stress stomatal frequency significantly increased. Maosong et al [19] and Khazaei et al [9] claimed that in wheat plant different ploidy levels showed significant diversity in 
stomatal frequency and diploid species showed highest number of stomata over tetraploid and hexaploid. That's why diploid species are more tolerant to water stress. Yousafzai et al [6] and Khazaei et al [9] concluded that higher stomatal frequency enhance the ability of wheat plant to withstand drought.

The perusal of Table 3 analysis of generation means indicated that three parameter model [mil] fitting best for stomatal frequency. It has been cleared that trait is under the control of non-additive gene action. The dominance $x$ dominance [1] showed higher and positive value that determined the stomatal frequency had a breeding importance in later generations. The negative value of additive $\times$ additive [i] genetic effect makes the result more complex and indicated that selection is of no use in early segregating generations because there is no additive genetic effect to be fixed. Mahmood et al. [25] reported that additive genetic effects along with the partial dominance involved in the inheritance of stomatal frequency. The non-allelic interaction out of which additive $x$ additive [i] and dominance $\times$ dominance [1] found to be outstanding Ambreen et al. [24].

\subsection{Stomatal Size $(\mu \mathrm{m})$}

According to the Table 1 parents $\mathrm{F}_{1}, \mathrm{~F}_{2}, \mathrm{BC}_{1}$ and $\mathrm{BC}_{2}$ derived from a between cross V-04189 $\left(\mathrm{P}_{1}\right) \times \mathrm{V}-03138\left(\mathrm{P}_{2}\right)$ showed significant differences at significance level $1 \%$. The perusal of Table 2 depicted that the stomatal size of hybrid $\mathrm{F}_{1}$ (752.95) was higher than $\mathrm{P}_{2}$ (748.88) and $\mathrm{P}_{1}(148.88)$ parent. Maosong et al. [19] and Khazaei et al. [9] claimed that in wheat plant different ploidy levels showed significant diversity in stomatal size and hexaploid species showed higher stomatal size over tetraploid and diploid species.

The genetic analysis showed that three parameters model [mhi] showed the best fit for stomatal size from observed to expected generation means (Table 3 ). The additive genetic effect [d] is absent showed that stomata size is under the control of non-additive gene action and heterosis can be utilized in hybrid combinations. This may be due to over-dominance, unidirectional or dispersion of genes in the parents. The positive and higher value additive $\times$ additive [i] genetic effect favors the selection in early segregating generation and it is possible to fix the additive $\times$ additive [i] genetic effect to increase the stomata size. Hasan and Khaliq. [32] reported that stomatal size controlled by non-additive genetic effects and Ambreen et al. [24] also reported the presence of non-allelic interaction in the inheritance of stomatal size.

\section{Conclusions}

The data analysis revealed, all the traits studied have significant differences among the six generations. Generation means analysis concluded that most of the physiological traits controlled by additive type of gene action that's why, the selection in early generations could be helpful for improvement. In future, breeding cultivars against rainfed environment, these genotypes could be given a due importance. 
Table 1. Analysis of variance for five physiological traits of six generations (P1, P2, F1, F2, BC1 and BC2) of wheat cross V-04189 (P1) × V-03138 (P2) evaluated under rainfed condition.

\begin{tabular}{|c|c|c|c|}
\hline \multicolumn{4}{|c|}{ MEAN SQUARES } \\
\hline CHARACTERS & $\begin{array}{c}\text { REPLICATION } \\
(\mathrm{df}=2)\end{array}$ & $\begin{array}{c}\text { GENOTYPES } \\
(\mathrm{df}=5)\end{array}$ & $\begin{array}{r}\text { ERROR } \\
(d f=10)\end{array}$ \\
\hline Flag leaf area $\left(\mathrm{cm}^{2}\right)$ & $0.62^{\text {N.S }}$ & $5.94 * *$ & 0.55 \\
\hline Relative water contents (RWC) & $0.082^{\mathrm{N} . \mathrm{S}}$ & $11.40 * *$ & 0.85 \\
\hline Excised leaf water loss (ELWL) & $0.24^{\mathrm{N.S}}$ & $1.29 * *$ & 0.18 \\
\hline Stomatal frequency & $15.1^{*}$ & $969.8 * *$ & 10.3 \\
\hline Stomatal size $(\mu \mathrm{m})$ & $178^{*}$ & $1206 * *$ & 228 \\
\hline
\end{tabular}

$* \mathrm{P} \leq 0.05, * * \mathrm{P} \leq 0.01, \mathrm{~N} . \mathrm{S}=$ Non-significant

Table 2. Generation means of five physiological traits of the wheat cross V-04189 (P1) $\times$ V-03138 (P2) evaluated under rainfed

\begin{tabular}{|c|c|c|c|c|c|c|}
\hline Traits & $\mathbf{P}_{1}$ & $\mathbf{P}_{2}$ & $\mathbf{F}_{1}$ & $\mathbf{F}_{2}$ & $\mathrm{BC}_{1}$ & $\mathbf{B C}_{2}$ \\
\hline Flag Leaf Area $\left(\mathrm{cm}^{2}\right)$ & 37.23 & 34.33 & 34.96 & 32.90 & 34.80 & 35.22 \\
\hline Relative water contents (RWC) & 82.65 & 80.73 & 83.22 & 82.71 & 79.21 & 79.53 \\
\hline Excised leaf water loss (ELWL) & 4.59 & 3.53 & 4.61 & 4.07 & 3.82 & 3.87 \\
\hline Stomatal Frequency & 80.66 & 75.11 & 125.44 & 98.44 & 94.44 & 94.66 \\
\hline Stomatal Size $(\mu \mathrm{m})$ & 751.10 & 748.88 & 752.95 & 703.00 & 725.57 & 724.09 \\
\hline
\end{tabular}

Table 3. Estimations of genetic components of the best fit model on generation means for six physiological traits of the wheat cross V-04189 (P1) $\times$ V- $03138(\mathrm{P} 2)$ evaluated under rainfed condition

\begin{tabular}{|c|c|c|c|c|c|c|c|}
\hline Traits & $\mathrm{m} \pm \mathrm{S} . \mathrm{E}$ & {$[\mathrm{d}] \pm$ S.E } & {$[\mathrm{h}] \pm \mathrm{S} . \mathrm{E}$} & [i] \pm S.E & {$[\mathrm{j}] \pm$ S.E } & [1] \pm S.E & $\chi^{2}(\mathrm{~d} . f)$ \\
\hline Flag leaf area $\left(\mathrm{cm}^{2}\right)$ & $66.41^{* *} \pm 0.51$ & $1.95^{* *} \pm 0.52$ & & $1.96^{* *} \pm 0.84$ & & & $4.273(3)$ \\
\hline Relative water contents (RWC) & $146.07 * \pm 0.55$ & $1.00 * \pm 0.83$ & & & & & $7.621(4)$ \\
\hline Excised leaf water loss (ELWL) & $27.85^{* *} \pm 0.14$ & $1.25 * * \pm 0.25$ & & & & & $4.882(4)$ \\
\hline Stomatal frequency & $48.92 * \pm 1.77$ & & & $-4.87 * \pm 2.22$ & & $12.28 * \pm 3.34$ & $5.596(3)$ \\
\hline Stomatal size $(\mu \mathrm{m})$ & $41.69^{* *} \pm 15.63$ & & $4.51^{* *} \pm 22.20$ & $5.82^{* *} \pm 16.72$ & & & $0.177(3)$ \\
\hline
\end{tabular}

$\mathrm{m}=$ Mean, $[\mathrm{d}]=$ Additive effects, $[\mathrm{h}]=$ Dominance effects, $[\mathrm{i}]=$ Additive $\times$ Additive effects, $[\mathrm{j}]=$ Additive $\times$ Dominance effects, $[1]=$ Dominance $\times$ Dominance effects.

$* \mathrm{P} \leq 0.05,{ }^{* *} \mathrm{P} \leq 0.01$ 


\section{REFERENCES}

[1] Pakistan Statistical Year Book. 2009. Federal Bureau of Statistics, Statistics Division, Government of Pakistan, Islamabad, Pakistan.

[2] Siddique, M.R.B., A. Hamid and M.S. Islam. 2000. Water stress effects on water relations of wheat. Bot. Bull. Acad. Sin. 41:35-39.

[3] Bajji, M., S. Luttls and J.M. Kinet. 2001. Water deficit effects on solute concentration to osmotic adjustment as a function of leaf aging in three durum wheat (Triticum durum Desf.) cultivars performing differently in arid conditions. Pl. Sci. 160(4): 669-681.

[4] Sairam, R.K. and G.C. Srivastava. 2001. Water stress tolerance of wheat (Triticum aestivum L.): Variations in hydrogen peroxide accumulation and antioxidant activity in tolerant and susceptible genotypes. J. Agron. Crop Sci. 186(1): 63-70.

[5] Tas, S and B. Tas. 2007. Some physiological responses of drought stress in wheat genotypes with different ploidity in Turkiye. World J. Agric. Sci. 3(2): 178-183.

[6] Yousufzai, M.K., K.A. Siddiqui and A.Q. Soomro. 2009. Flag leaf stomatal frequency and its inter-relationship with yield and yield components in wheat (Triticum aestivum L.). Pak. J. Bot. 41(2): 663-666.

[7] Talebi, R., F. Fayaz and A. M. Naji. 2009. Effective selection criteria for assessing drought stress tolerance in durum wheat (Triticum durum Desf.). Gen. \& Appl. P1. Physiol. 35(1-2): 64-74.

[8] Khattab, S.A.M., R. M. Esmail and E.M.F. Al-Ansary. 2010. Genetical analysis of some quantitative traits in bread wheat (Triticum aestivum L.). N. Y. Sci. J. 3(11): 152-157.

[9] Khazaei, H., P. Monneveux, S. Hongbo and S. Mohammady. 2010. Variation for stomatal characteristics and water use efficiency among diploid, tetraploid and hexaploid Iranian wheat landraces. Genet. Resour. Crop Evol. 57: 307-314.

[10] Farshadfar, E., M. Ghanadha, M. Zahravi and J. Sutka. 2001. Generation mean analysis of drought tolerance in wheat (Triticum aestivum L.). Acta Agronomica Hungarica, 49(1): 59

[11] Kumar, A. and S.C. Sharma. 2007. Genetics of excised leaf water loss and relative water content in bread wheat (Triticum aestivum L.). Cereal Research Communication, 35(1): 43-52.

[12] Sharma, S.N. and R.K. Sharma. 1995. Genetic architecture of harvest index in tetraploid wheat (Triticum durum Desf.). Ind. J. Genet. 55(3): 233-237.

[13] Mather, K. and J.L. Jinks. 1982. Biometrical genetics, 3rd edition, Chapman and Hall Ltd., London.

[14] Muller, J. 1991. Determining leaf surface area by means of a wheat osmoregulation water use: the challenge. Agric. Meterolo. 14: 311-320.

[15] Rahman, S.U., M.S. Shaheen, M.U. Rahman and T.A. Malik. 2000. Evaluation of excised leaf water loss and relative water content, as screening techniques for breeding drought resistant wheat. Pak. J. Biol. Sci. 3(4): 663-665.
[16] Steel, R.D.G., J.H. Torrie and D.A. Dickey 1997. 3rd ed. Principles and Procedures of Statistics. A Biometrical Approach. McGraw-Hill, New York.

[17] Nabipour, A.R., B. Yazdi-Shamadi, A.A. Zali and K. Poustini. 2002. Effects of morphological traits and their relations to stress susceptibility index in several wheat genotypes. BIBAN, 7 (1): 31-47.

[18] Kazmi, R.H., M.Q. Khan and M.K. Abbasi. 2003. Effect of water stress on the performance of wheat grown under controlled conditions at Rawalakot, Azad Jammu and Kashmir. Sarhad J. Agric. 19(1): 61-68.

[19] Maosong, L., W. Chunyan, S. Jiqing, W. Xiufen and W. Yongfeng. 2008. Evolutional trends of leaf stomatal and photosynthetic characteristics in wheat evolutions. Acta Ecologica Sinica, 28(11): 5385-5391.

[20] Chowdhry, M.A., M.S. Akthar and M.T. Ahmad. 1992. Combining ability analysis for flag leaf area, yield and its components in spring wheat. J. Agric. Res. 30(1): 17-23.

[21] Awaad, H.A. 1996. Genetic system and prediction for yield and its attributes in four wheat crosses (Triticum aestivum L.). Annals Agric. Res. 34(3): 869-890.

[22] Chowdhry, M.A., I. Rasool, I. Khaliq, T. Mahmood and M.M. Gilani. 1999. Genetics of some metric traits in spring wheat under normal and drought environments. Rachis, 18(1): 34-39.

[23] Subhani, G.M. and M.A. Chowdhry. 2000. Genetic studies in bread wheat under irrigated and drought stress conditions. Pak. J. Biol. Sci. 3(11): 1793-1798.

[24] Ambreen, A., M.A. Chowdhry, I. Khaliq and R. Ahmad. 2002. Genetic determination for some drought related leaf traits in bread wheat. Asian J. P1. Sci. 1(3): 232-234.

[25] Mahmood, N., M.A. Chowdhry and M. Kashif. 2003. Genetic analysis of some physio-morphic traits of wheat under drought conditions. J. Genet. Breed. 57(4): 385-391.

[26] Riaz, R., and M.A. Chowdhry. 2003. Genetic analysis of some economic traits of wheat under drought condition. Asian J. P1. Sci. 2(10):790-796.

[27] Inamullah, F. Mohammad, G. Hassan, S. Din and S. Akbar. 2005. Genetics of important traits in bread wheat using diallel analysis. Sarhad J. Agric. 21(4): 617-622.

[28] Saleem, M., M.A. Chowdhry, M. Kashif and M. Khaliq. 2005. Inheritance pattern of plant height, grain yield and some leaf characteristics of spring wheat. Int. J. Agric. Biol. 7(6): 1015-1018.

[29] Munir, M., M.A. Chowdhry and M. Ahsan. 2007. Generation mean studies in bread wheat. Int. J. Agri. Biol. 9(2): 282-286.

[30] Malik, T.A. and D. Aeright. 1998. Physiological traits and breeding for drought resistance in wheat. Sarhad J. Agric. 14(4): 327-334.

[31] Golparvar, A.R., A. Ghasemi-pir-balouti and H. Madani. 2006. Genetic control of some physiological attributes in wheat under drought stress conditions. Pak. J. Biol. Sci. 9(8): 1442-1446.

[32] Hassan, S.E. and I. Khaliq. 2008. Quantitative inheritance of some physiological traits for spring wheat under two different population densities. Pak. J. Bot. 40(2): 581-587. 